\title{
Effect of Antipsychotics on Regional Cerebral Blood Flow Measured with Positron Emission Tomography
}

\author{
Del D. Miller, Pharm.D., M.D., Nancy C. Andreasen, Ph.D., M.D., Daniel S. O'Leary, Ph.D, \\ Karim Rezai, M.D, G. Leonard Watkins, Ph.D., Laura L. Boles Ponto, Ph.D, and \\ Richard D. Hichwa, Ph.D.
}

Positron Emission Tomography (PET) imaging of regional cerebral blood flow ( $r C B F)$ provides an in vivo method for studying brain function. We used $\left[{ }^{15} \mathrm{O}\right] \mathrm{H}_{2} \mathrm{O}$ PET to assess the effect of antipsychotic medications on $\mathrm{rCBF}$ in 17 subjects with schizophrenia. Each subject was scanned while receiving antipsychotic medication, and after having been withdrawn from antipsychotic medication for a 3-week period. The two scans were subtracted from one another, using a within subjects design, and the areas of difference were identified using the Montreal method. Subjects treated with antipsychotic medication had significantly higher $r C B F$ in the left basal ganglia and left fusiform gyrus compared with the "off-medication" condition.

Significantly higher relative $\mathrm{rCBF}$ in the anterior cingulate, left dorsolateral and inferior frontal cortex, and left and right cerebellum was observed when off antipsychotic medication. Upregulation of dopamine $D_{2}$ receptors may lead to a regional increase of blood flow and metabolism in the basal ganglia, which may explain recently reported anatomical enlargement in these regions.

[Neuropsychopharmacology 17:230-240, 1997]

(C) 1997 American College of Neuropsychopharmacology Published by Elsevier Science Inc.
KEY WORDS: Regional cerebral blood flow; $\left[{ }^{15} \mathrm{O} \mathrm{H}_{2} \mathrm{O}\right.$ PET; Schizophrenia; Antipsychotics

Numerous studies have examined cerebral blood flow and metabolism in schizophrenia, originally with cortical probes and later with Single Photon Emission Computed Tomography (SPECT) and Positron Emission Tomography (PET) (Ingvar and Franzen 1974; Buchsbaum

From the Mental Health Clinical Research Center-Major Psychoses (DDM, NCA, DSOL), Department of Psychiatry (DDM, NCA), Department of Radiology (KR), College of Medicine, University of Iowa, Iowa City, Iowa; the Positron Emission Tomography Imaging Center (GLW, LLBP, RDH), University of Iowa Hospitals and Clinics, Iowa City, Iowa.

Address correspondence to: Del D. Miller, Pharm.D., M.D., University of Iowa Hospitals and Clinics, Department of Psychiatry Administration, 200 Hawkins Drive \#2880 JPP, Iowa City, Iowa 52242.

Received June 14, 1996; revised January 17, 1997; accepted February $13,1997$. et al. 1982; Weinberger et al. 1986; Buchsbaum et al. 1987; Weinberger et al. 1988; Andreasen et al. 1992). These studies have suggested that some patients with schizophrenia have decreased regional blood flow and/ or reduced metabolic function, particularly in the frontal lobes and/or the left hemisphere. There is also a suggestion of abnormalities in blood flow and/or metabolic rates in various subcortical areas such as the hippocampus, parahippocampus, and globus pallidus (Wolkin et al. 1985; Buchsbaum at al. 1987). (See Andreasen et al. 1992 for a review of the topic). In early functional imaging studies many patients were evaluated while taking medications, raising the possibility that the abnormalities noted, such as "hypofrontality," were secondary to the effects of antipsychotics. This concern was enhanced by reports of increased metabolic activity in prefrontal regions in drug naive first episode patients (Cleghorn et al. 1989), although others 
have noted decreased blood flow or metabolism in frontal regions in drug naive patients (Andreasen et al. 1992).

While it is clear that both typical and atypical antipsychotics are effective in reducing symptom severity and psychotic exacerbations in a majority of patients with schizophrenia, our understanding of the mechanisms underlying these effects remains limited. There have been at least ten studies using PET that have examined the relationship between antipsychotic medication status and brain metabolism in patients with schizophrenia (Brodie et al. 1984; DeLisi et al. 1985; Sedvall et al. 1985; Wolkin et al. 1985; Volkow et al. 1986; Buchsbaum et al. 1987; Gur et al. 1987; Bartlett et al. 1991; Buchsbaum et al. 1992a; Buchsbaum et al. 1992b). These studies are reviewed in detail elsewhere (Miller et al. 1997). Findings have been somewhat variable, with perhaps the most consistent being that of increased metabolism in the basal ganglia during the medicated vs. unmedicated state. PET studies examining the effects of antipsychotics on receptors have shown that most antipsychotics block approximately $80 \%$ of the $D_{2}$ receptors in the basal ganglia, that this effect occurs almost immediately, and that the antipsychotics also debind relatively quickly (i.e., within days) (Farde et al. 1986). It is possible that the effect of antipsychotic medication on blood flow and metabolism in the basal ganglia is related to $D_{2}$ receptor blockade in these regions, producing chronic upregulation after long-term usage with an associated increase in metabolic need.

Several recent anatomic studies have presented additional data that may inform the understanding and interpretation of functional imaging studies. Jernigan and colleagues (Jernigan et al. 1991) were the first to observe an increase in the size of basal ganglia structures, as measured with magnetic resonance imaging (MRI), in a group of patients chronically treated with antipsychotic medication. Our own group, independently and simultaneously, made the same observation and subsequently reported it as well (Swayze et al. 1992). These findings have now been confirmed in a series of subsequent studies (Breier et al. 1992; Chakos et al. 1994; Elkashef et al. 1994; Hokuma et al. In press), as well as in a post mortem study (Heckers et al. 1991). The Chakos study (Chakos et al. 1994) examined first episode patients with an initial scan and conducted a follow-up scan 18 months later, demonstrating that caudate volume had increased during that time interval and that the increase in size was related to antipsychotic dose, suggesting that the increased size of the basal ganglia may be antipsychotic-induced. Buchanan et al. (1993) subdivided Breier's patients (Breier et al. 1992) into deficit or nondeficit schizophrenia and observed the deficit patients to have relatively greater caudate size. These findings are particularly intriguing, since most brain regions are found to be decreased in persons with schizophrenia, including cerebral tissue, frontal lobes, and temporal robes (Pearlson, and Marsh 1993; Andreasen et al. 1994a; Andreasen et al. 1994b).

Most previous studies with MRI, SPECT, or PET have used a case-control design, which has less power because of the greater variance that occurs when two different groups are compared with one another. A within-subjects design, comparing subjects to themselves while on and off medication, appears to be optimal for addressing questions concerning the effects of medication on cerebral blood flow and metabolism. We have previously used a within-subjects design with TC-99M HMPAO SPECT to determine the effects of antipsychotic medications on cerebral perfusion (Miller et al. 1997). We studied a group of 33 schizophrenics, each scanned twice, once while receiving a stable dose of antipsychotic and once after being off antipsychotics for at least three weeks. We reported that mean blood flow was significantly greater in the left basal ganglia in the on-medication state. While we referred to changes in blood flow in the basal ganglia, these localizations were approximations because of the poor spatial resolution of the TC99M HMPAO SPECT method. Although the results of this study provide interesting preliminary data confirming an effect of antipsychotics on blood flow in the basal ganglia, they clearly need replication with more precise techniques such as are afforded by PET.

This early work with structural and functional neuroimaging has raised many crucial questions, most of which have not yet been definitively addressed. What are the sites of primary neural abnormality in patients suffering from schizophrenia? What are the sites through which antipsychotic medications exert their therapeutic effects? Do the therapeutic effects of antipsychotics differ for different types of symptoms (e.g., psychotic, negative or deficit, disorganized, cognitive) in ways that can be separated using neuroimaging techniques? What is the relationship between receptor blockade and cerebral blood flow and metabolism? Do antipsychotic medications have measurable effects on brain anatomy as well as physiology? Are the various effects on brain anatomy and physiology reversible and, if so, over what time interval? Obviously these myriad questions represent a long-term agenda for structural and functional imaging studies of the psychopharmacology of schizophrenia. In the present report we examine one small piece of this puzzle: the effect of antipsychotics on regional cerebral blood flow in schizophrenic patients, using a within-subjects design to examine regional changes while on and off medications. We sought to determine which specific regions differ while on and off medications. To our knowledge, this is the first study using $\left[{ }^{15} \mathrm{O}\right] \mathrm{H}_{2} \mathrm{O}$ PET scanning to measure the effect of 
antipsychotic medication on regional blood flow in subjects suffering from schizophrenia.

\section{METHODS}

\section{Subjects}

As can be seen in Table 1, the sample consisted of a group of 17 subjects who met DSM-IV criteria for schizophrenia (APA 1994). Three subjects were "antipsychotic naive" and 14 subjects were nonnaive patients who had been chronically ill. The mean age was 32.8 years (SD, 10.7 years), and the mean educational achievement was 12.8 years (SD, 2.0 years). Thirteen patients were male, and 4 were female. The mean educational level of their fathers was 13.5 years (SD, 2.6 years). The patients average height was $182.5 \mathrm{~cm}$ (SD, $14.8 \mathrm{~cm}$ ), and the average weight was $79.6 \mathrm{~kg}$ (SD, 15.7 $\mathrm{kg}$ ). Mean age of onset was 23.5 years (SD, 6.9 years ) and mean duration of illness was 97.6 months (SD, 139.3 months). On average they had five hospitalizations during their lifetimes (SD, 8.1), and the mean lifetime duration of hospitalization was 13.2 months (SD, 35.6 months). All patients have been followed for at least six months, and their diagnosis of schizophrenia has been confirmed. All gave written informed consent to the protocol approved by the University of Iowa Human Subjects Institutional Review Board.

\section{Medication Status}

Antipsychotic naive patients $(n=3)$ were first scanned prior to starting antipsychotic medication. Patients who had been on chronic antipsychotic treatment $(n=14)$ had the off-medication scan after undergoing a threeweek medication "washout" period. Some of these patients were scanned first while on a dose of antipsychotic that had been adjusted to optimize clinical response and had not changed in three weeks, and subsequently after undergoing the three-week drug washout $(n=4)$. The others underwent the drug washout first and had the second scan after being on a dose of antipsychotic medication, adjusted to clinical response, for three weeks $(n=10)$. Patients were on a variety of antipsychotic medications when the on-medication scans were completed ( 7 haloperidol, 3 olanzapine, 2 risperidone, 2 trifluoperazine, 1 thiothixene, 1 clozapine, and 1 loxitane). The mean antipsychotic dose was $1288.24 \pm 1561.60$ chlorpromazine equivalents per day (range $=300$ to 6000).

Table 1. Diagnoses, Antipsychotic Medications, Concurrent Medications, and Psychopathology Off- and On-Medication for the 17 Subjects

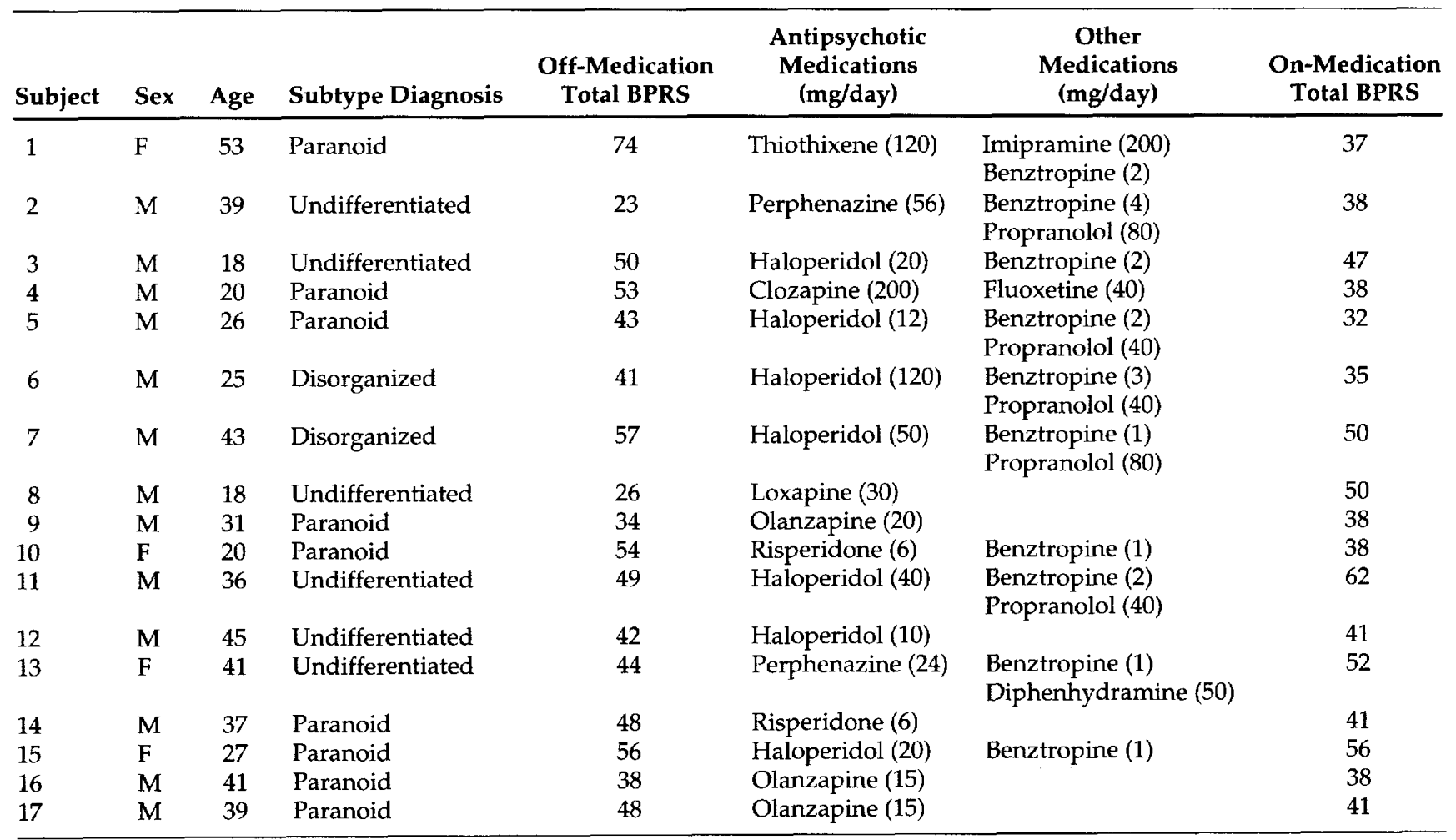




\section{Clinical Measures}

All patients were evaluated during an admission to the University of Iowa Mental Health Clinical Research Center. Patients were assessed clinically by means of the Comprehensive Assessment of Symptoms and History (CASH) (Andreasen et al. 1992a). All patients were withdrawn from all psychotropic medications for a three week period. Patients receiving depot antipsychotics during the past 6 months were not included in the protocol.

\section{Image Acquisition and Reconstruction}

Subjects were positioned in the GE-4096 PLUS PET scanner in a supine position with laser light guides (indicating the center of the lowest slice) aligned at the orbital-meatal line. The subject's head was taped to a foam-lined head holder made of rigid plastic. A transmission scan was first obtained using a rotating rod source of $\left[{ }^{68} \mathrm{Ge}\right]$ germanium in order to correct the $\left[{ }^{15} \mathrm{O} \mathrm{H}_{2} \mathrm{O}\right.$ emission images for attenuation. This was followed by a "sham" injection during which patients were performing a memory task. During the sham, all procedures were identical to an image acquisition condition from the subject's perspective but only $15 \mathrm{mCi}$ of $\left[{ }^{15} \mathrm{O}^{\mathrm{H}} \mathrm{H}_{2} \mathrm{O}\right.$ was injected and no arterial blood was drawn. The sham helped to reduce the subject's anxiety and consequent high overall cerebral blood flow that we had consistently found during the first injection in pilot work.

Regional cerebral blood flows (rCBF) were acquired while the patients were lying in the scanner with their eyes closed. A bolus injection of $50 \mathrm{mCi}$ of $\left[{ }^{15} \mathrm{O}\right] \mathrm{H}_{2} \mathrm{O}$ in 5-7 $\mathrm{mL}$ of saline was administered, using the bolus $\left[{ }^{15} \mathrm{O}^{-} \mathrm{H}_{2} \mathrm{O}\right.$ method (Ginsberg et al. 1982; Raichle et al. 1983). Fifteen slices (6.5 mm center-to-center) were acquired with an intrinsic in-plane resolution of $6.5 \mathrm{~mm}$ FWHM and a $10 \mathrm{~cm}$ axial field of view. Emission im- ages were reconstructed using a Butterworth filter (cutoff frequency $=0.35$ Nyquist) for a 40 second interval that began after the bolus of $\left[{ }^{15} \mathrm{O} \mathrm{H}_{2} \mathrm{O}\right.$ arrived in the brain, following injection into a catheter in the antecubital vein of the right arm. Arterial blood was sampled to allow calculation of tissue perfusion in milliliters per minute per 100 grams $(\mathrm{mL} / \mathrm{min} / 100 \mathrm{~g})$ of tissue using the autoradiographic method (Herscovitch et al. 1983).

The eyes closed condition was part of a four-injection study designed to assess various aspects of memory. The results of the other conditions will be clescribed in another report.

\section{Image Analysis}

The quantitative PET blood flow images were transferred to the Image Processing Laboratory of the University of Iowa Mental Health Clinical Research Center for analysis using locally-developed software (Andreasen et al. 1993). MRI images, acquired for each subject on a 1.5 Tesla General Electric Signa scanner, were also transferred to the Image Processing Laboratory. The MRI images were contiguous $1.5 \mathrm{~mm}$ thick coronal slices. Technical parameters of the MRI image acquisition were: an SPGR sequence with flip angle of $40^{\circ}$, TE of $5 \mathrm{~ms}$, TR of $24 \mathrm{~ms}, 2$ excitations.

The first step in the analysis involved separating the brain from skull and background on the MRI and PET images. The outlines of the brain were manually traced on the MRI images, and the outlines of the PET brains were automatically identified with an edge detection algorithm (Cizadlo et al. 1994).

The MRI and PET brain outlines were then co-registered using software that performed a least-squares minimization to fit the surface of the PET and MRI images (Pelizzari et al. 1989; Andreasen et al. 1993; Cizadlo et at. 1994). The PET image for each subject was co-

Table 2. Regions with Significant Differences Between On-Medication Resting Condition and Off-Medication Resting Condition ${ }^{a}$

\begin{tabular}{lrrrrr}
\hline \multicolumn{1}{c}{ Region } & $\boldsymbol{x}$ & $\boldsymbol{y}$ & $\boldsymbol{z}$ & $\boldsymbol{t}$-max & $\begin{array}{c}\text { Number } \\
\text { of Voxels }\end{array}$ \\
\hline $\begin{array}{l}\text { Positive Values (On-medication flow higher) } \\
\quad \text { Left putamen }\end{array}$ & -13 & 5 & -6 & 4.7 & 327 \\
$\quad$ Left fusiform gyrus & -28 & -83 & -2 & 4.0 & 103 \\
Negative Values (Off-medication flow higher) & -27 & 18 & 38 & -4.5 & 206 \\
$\quad$ Left dorsolateral frontal & 10 & 36 & -28 & -4.2 & 122 \\
$\quad$ Inferior frontal & 3 & 43 & 16 & -5.7 & 5142 \\
$\quad$ Anterior cingulate & -24 & -84 & -26 & -4.6 & 980 \\
$\quad$ Left cerebellum & 26 & -80 & -24 & -5.5 & 1689 \\
$\quad$ Right cerebellum & & & & & \\
\hline
\end{tabular}

\footnotetext{
${ }^{a}$ Data show the highest $t$-value ( $t$-max) associated with each peak and the location of the voxel with the highest $t$-value in terms of Talairach coordinates. Coordinates are shown only for peaks consisting of 50 or more contiguous voxels that exceed a $t$-value of $3.61 ; x$ represents left/right, $y$ front/back and $z$ superior/inferior.
} 
A

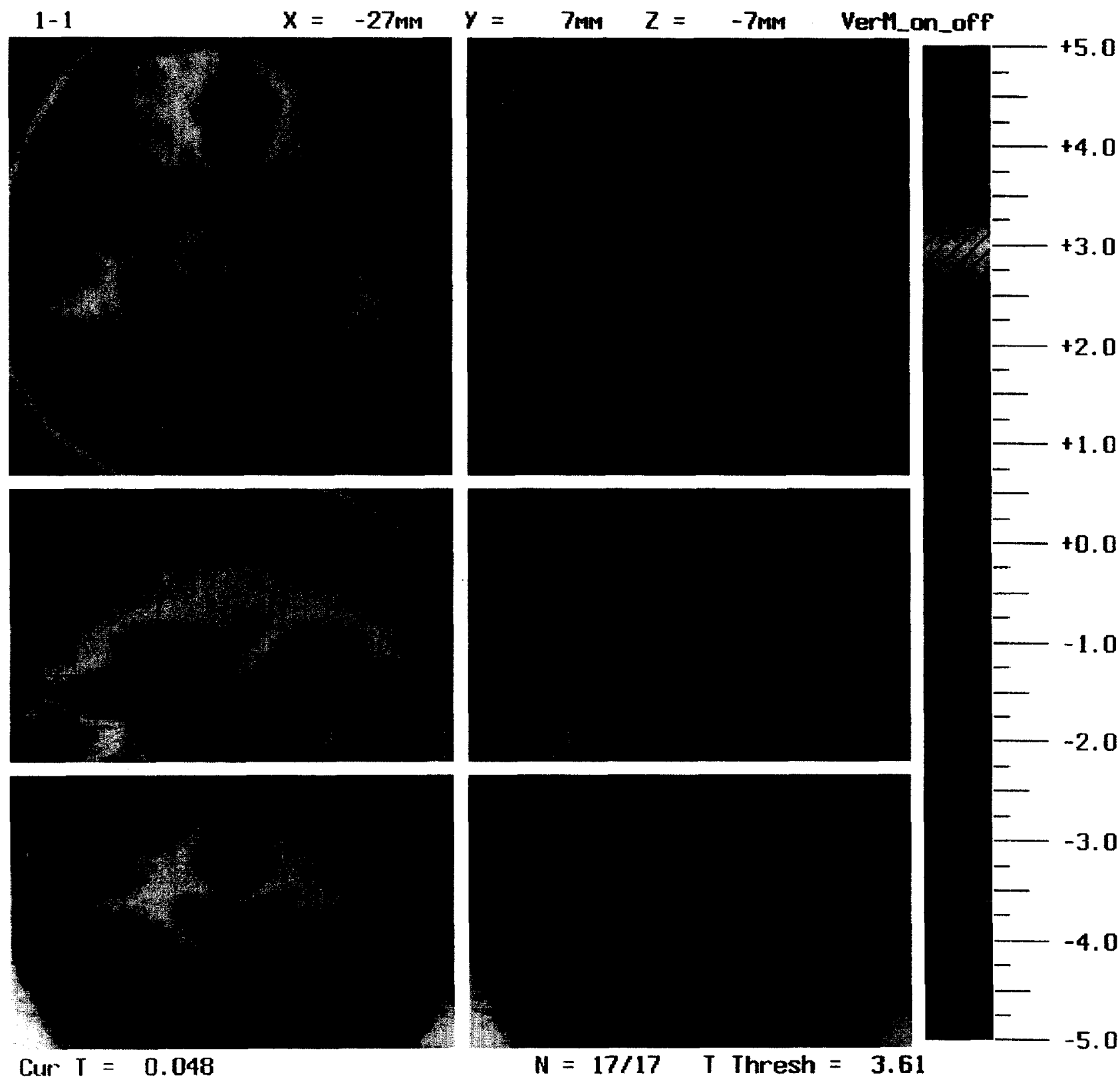

Figure 1. PET images showing on-medication resting condition minus off-medication resting condition in 17 subjects with schizophrenia. Three orthogonal views are shown, with transaxial at the top, sagittal in the middle, and coronal on the bottom. Green crosshairs are in the same location in the three views. The locations were chosen to optimally visualize the relevant brain regions. Images follow radiological convention and show location as if the viewer were standing at the foot of the bed (transaxial views) or facing the patient (coronal views). Statistical maps ( $t$ maps) of the PET data, showing regions that are significantly different, are superimposed on a composite MRI image derived by averaging the MRI scans from the subjects. The value of $t$ is shown on the color bar on the right. Two types of statistical maps are provided. The "peak maps" (left side of images) show the small areas where all contiguous voxels exceed the predefined threshold for statistical significance (3.61). The " $t$ maps" (right side of images) show the value of $t$ for all voxels in the image and provides a general overview of the landscape of changes in blood flow during the on-medication in comparison to the off-medication resting condition. In this figure, regions in which flow was higher in the on-medication condition are positive (red tones), and regions in which flow was higher in the off-medication condition are negative (blue tones). (A) Positive peaks are seen in the left putamen and left fusiform gyrus and negative peaks are seen in the left dorsolateral frontal region. (B) Negative peaks are seen in the inferior frontal region, anterior cingulate, and left and right cerebellum. 
B

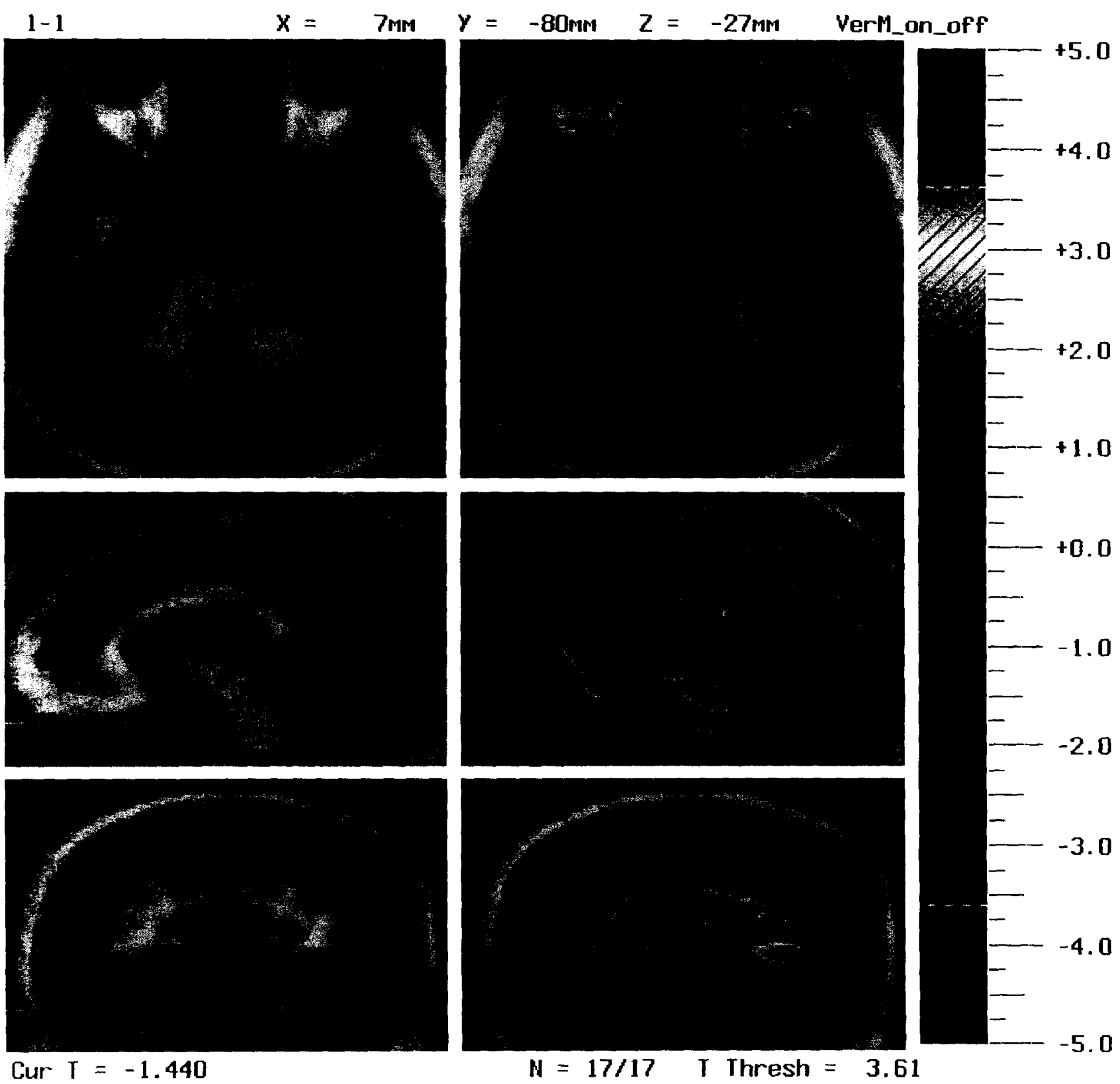

registered to his or her MRI to compensate for small movements that might have occurred. Following coregistration, each MRI brain image was placed into standardized Talairach atlas (Talairach J 1988) using a three-dimensional (3-D) linear transformation (Andreasen et al. 1995). This procedure involved first identifying the anterior and posterior commissures, and the interhemispheric fissure on each MRI image, and then resampling the $1.5 \mathrm{~mm}$ coronal acquisition images into a 3-D volume with $1.016 \mathrm{~mm}$ cubic voxels. During this step the brain images were aligned in a standard 3-D orientation. The superior and inferior points on each brain were then identified, as were the leftmost and rightmost and anteriormost and posteriormost points of the brains, and these points were used to linearly transform each MRI and co-registered PET brain image into a standard "bounding-box".

\section{Statistical Analysis}

Statistical analysis of the images was performed by using an adaptation of the Montreal method (Worsley et al. 1992). An $18 \mathrm{~mm}$ Hanning filter was applied to the PET images for each condition to compensate for residual anatomical variability by removing high spatial frequency detail. A within-subject subtraction of the off- 
medication resting baseline condition from the on-medication resting baseline condition was then performed, followed by across-subject averaging of the subtraction images and computation of voxel by voxel $t$-tests of the rCBF changes. In order to determine areas of significant effects across individuals, a $t$ map was generated, using a technique developed by Worsley and associates (Worsley et al. 1992). Regions with $t$-values of greater than 3.61, which corresponds to a $p<0.0005$ (uncorrected), were considered significant.

In the tabled data, the positive and negative $t$ values are referred to by the condition in which regional flow was higher. The tables indicate the brain regions that had significantly higher flow in either condition, relative to the other, using region names based on inspection of the co-registered MRI and PET images, as well as the $x, y$, and $z$ coordinates from the Talairach atlas. Areas containing at least 50 continuous voxels with a $t$-value greater than 3.61 are reported in the tables, as well as the highest $t$-value $(t$-max) and the total number of voxels in the region.

Visual display of results is shown in two ways. One presentation shows only the peaks, as defined by the volume measurement, superimposed on the composite average MRI brain from the 17 subjects. The other presentation, referred to as the " $t$ map," shows the colorcoded $t$-values for all voxels in the image. The peak map and the $t$ map provide complementary information. The former identifies areas of difference in flow by using a strict definition based on a relatively arbitrary cutoff point, while the latter provides a more descriptive picture of the geography of the circuitry involved.

\section{RESULTS}

The results of the image-subtraction analysis are shown in Table 2 and displayed in Figure 1. Since the off-medication scan was subtracted from the on-medication scan, the brain regions that had relatively higher flow on medications are shown as positive values and those with relatively higher flow off medications are shown as negative values.

As can be seen in Table 2 and Figure 1, when on medications patients had significantly higher flow in the left basal ganglia and left fusiform gyri. Although these results appear to suggest that the activation of the basal ganglia was unilateral, inspection of the $t$ map data indicates a similar but much smaller area of increased flow on the right; its maximal $t$-value $(3.63, p<0.0007)$ reached the significance threshold selected as standard for this and other studies currently completed by our group, but this area of increased flow was quite small (7 contiguous voxels). The increase in flow in the putamen is consistent with our earlier SPECT studies (Miller et al. 1997) and with other studies suggesting increased metabolic activity in the basal ganglia in response to antipsychotic treatment (Farde et al. 1986; Holcomb et al. 1996). The increase in flow in the fusiform region has not been previously reported.

Significant differences were also seen in the subjects when they were medication-free. Negative $t$-values were seen for large regions in the anterior cingulate, left dorsolateral frontal, inferior frontal, and right and left lateral cerebellum. Since the subtraction analysis can indicate only relative differences between the two conditions, we could not determine from these analyses whether the changes represent an absolute decrease in the on-medication state with respect to the off-medication state or an absolute increase in the off-medication state with respect to the on-medication state. Since we have absolute blood flow data for all subjects, however, we were able to measure this directly, and these results are shown in Table 3. This table reports the average tissue perfusion in $\mathrm{ml} / \mathrm{min} / 100 \mathrm{~g}$ of tissue for the various regions that were found to have significantly different blood flow by the $t$ map analysis in the seventeen subjects. These data reflect the mean and standard deviation of the spatially normalized data at the location of the highest $t$ in each region. The data in the table are not intensity normalized by whole brain blood flow, but the results after normalization are essentially the same. (Mean whole brain blood flow for the subjects while on and off medication was $53.2 \pm 11.4$ and $51.8 \pm 9.3 \mathrm{~mL} /$ $\mathrm{min} / 100 \mathrm{~g}$ of tissue, respectively.)

The results reported in Table 3 indicate that antipsychotic medications produce absolute increases in blood flow in basal ganglia and left fusiform gyri, and that absolute increases occur in the anterior cingulate, left dorsolateral and inferior frontal cortex, and cerebellum when antipsychotics are withdrawn.

\section{DISCUSSION}

Mapping the effects of antipsychotic medication gives us many different kinds of information. One type of information is about the neurochemical circuits affected by antipsychotics. It can be hypothesized that some of the regions in which blood flow is increased during treatment reflect increased metabolic activity in the dopamine receptors embedded in neuronal membranes, which are upregulated as a consequence of chronic blockade leading to a corresponding upsurge in metabolic need. This is possibly the case with the increased flow observed in the basal ganglia. Increases in metabolism in the basal ganglia as measured with $\left[{ }^{18} \mathrm{~F}\right]$ fluorodeoxyglucose, increased receptor blockade as measured with $\left[{ }^{11} \mathrm{C}\right]$ raclopride, or increased blood flow as measured with SPECT have now been noted in a number of studies (Brodie et al. 1984; DeLisi et al. 1985; Wolkin et 
Table 3. Tissue Perfusion in the On- and Off- Medication Conditions for Regions with Significant Differences ${ }^{a}$

\begin{tabular}{lcccc}
\hline \multicolumn{1}{c}{ Region } & $\begin{array}{c}\text { On-Medication } \\
\text { Tissue Perfusion }\end{array}$ & $\begin{array}{c}\text { \% of Whole Brain } \\
\text { Blood Flow }\end{array}$ & $\begin{array}{c}\text { Off-Medication } \\
\text { Tissue Perfusion }\end{array}$ & $\begin{array}{c}\text { \% of Whole Brain } \\
\text { Blood Flow }\end{array}$ \\
\hline Left putamen & $63.8 \pm 13.2$ & 119.9 & $60.6 \pm 15.4$ \\
Left fusiform gyrus & $49.5 \pm 10.8$ & 93.0 & $44.8 \pm 7.7$ & 116.9 \\
Left dorsolateral frontal & $62.5 \pm 9.9$ & 117.5 & $68.5 \pm 16.9$ & 86.5 \\
Inferior frontal & $36.4 \pm 10.8$ & 68.4 & $43.5 \pm 16.9$ & 132.2 \\
Anterior cingulate & $62.5 \pm 10.8$ & 117.5 & $72.5 \pm 22.3$ & 84.0 \\
Left cerebellum & $61.2 \pm 14.1$ & 115.0 & $68.5 \pm 15.4$ & 130.0 \\
Right cerebellum & $67.7 \pm 15.1$ & 127.2 & $76.4 \pm 19.9$ \\
Whole brain & $53.2 \pm 11.4$ & & $51.8 \pm 9.3$ \\
\hline
\end{tabular}

${ }^{a}$ Values are mean \pm SD milliliters per minute per 100 grams of tissue $(\mathrm{ml} / \mathrm{min} / 100 \mathrm{~g})$.

al. 1985; Farde et al. 1986; Buchsbaum et al. 1987; Wik et at. 1989; Holcomb et al. 1996; Miller et al. 1997).

Further work is needed in order to illuminate the precise mechanism by which the increase occurs, as well as its related effects. One fundamental question is whether the increased metabolism is a direct consequence of $\mathrm{D}_{2}$ blockade. If the increase in metabolism/perfusion in the basal ganglia associated with antipsychotic treatment is related to $D_{2}$ antagonism in this region, medications that are more potent $\mathrm{D}_{2}$ receptor antagonists would be expected to have a greater effect on blood flow or metabolism. Future studies examining whether antipsychotics with differing dopamine $\mathrm{D}_{2}$ blocking potency have differing effects on blood flow in the basal ganglia should be useful in addressing this question. A comparison of typical vs. atypical antipsychotics should be especially helpful. Another possibility is that the antipsychotic medications may be changing relative cerebral blood flow in the basal ganglia or other regions indirectly via neural circuit mechanisms. For example, Holcomb and colleagues (Holcomb et al. 1996) in a study examining the effects of withdrawal from haloperidol over a thirty day period, observed that this particular typical antipsychotic produces increased glucose metabolism in caudate, putamen, and thalamus, while withdrawal from it produces increased metabolism in anterior cingulate, and medial and inferior frontal cortex. They argue that the basal ganglia changes are primary, while the cortical, thalamic, and cingulate changes are secondary and reflect downstream consequences of a primary action on the basal ganglia. Their argument is based primarily on two lines of evidence: a low density of $\mathrm{D}_{2}$ receptors in some of the regions showing changes (e.g., thalamus), and anatomic information about the interconnectivity of the various pathways involved (e.g., thalamic glutamatergic efferents to cingulate and frontal cortex). More detailed mapping of receptor antagonists and agonists with specific ligands, coupled with the more indirect methods of examining effects of various classes of medications on blood flow and metabolism, will be needed to determine the precise nature of the primary and secondary effects.
While not conclusive, the results of this study are congruous with the speculation that receptor blockade may produce measurable effects on brain structure in regions where blood flow and metabolism are increased. That is, these findings may provide a partial explanation for the observation of increased size of the basal ganglia in schizophrenia, which has been reported in numerous studies (Jernigan et al. 1991; Breier et al. 1992; Swayze et al. 1992; Chakos et al. 1994; Keshavan et al. 1994; Hokuma et al. In press). Both Chakos (1994) and Keshavan et al. (1994) have conducted longitudinal studies of first episode patients, and the Keshavan subjects were initially antipsychotic naive as well; both groups reported progressive increase in basal ganglia size over time. Coupled with the functional imaging data, the findings suggest that antipsychotic treatment may lead to structural changes. The precise nature of the changes requires further study. Various explanations are possible; for example, the increased flow may lead to vascular engorgement; or chronic blockade may produce such intense receptor proliferation that changes in the dendritic tree lead to a measurable size increase. A study combining MRI and PET measurements in a single group of subjects withdrawn from medication might assist in addressing these questions.

The interconnections of the basal ganglia are wellestablished (Alexander et al. 1986; Alexander and Crutcher 1990; Goldman-Rakic and Selemon 1990; Graybiel 1990; Smith and Bolam 1990: Andreasen et al. 1995), and this brain region is well-positioned in order to have downstream effects on cognition and emotion, in addition to motor behavior, by virtue of these connections. Changes in blood flow were observed in this study in a variety of regions in addition to the basal ganglia, however. For example, patients also had higher flow in the left fusiform gyrus while on medication. The reasons for this are unclear. This region is association cortex, and its increased flow presumably reflects an effect of antipsychotics on cognitive activities mediated by this region. In this study the subjects were lying with their eyes closed and thinking about whatever came to mind; although this condition is often referred to as 
"resting," with the implication that the brain is relatively inactive, we have elsewhere discussed the likelihood that most subjects are engaged in thinking about events from the past or planning for the future and that the condition probably therefore activates memory circuits of the brain (Andreasen et al. 1995). Antipsychotic medications may permit these regions to function more effectively.

Antipsychotic medications also affect other aspects of brain function, either as a consequence of receptor blockade or in addition to receptor blockade. They clearly diminish psychotic symptoms; however, their effects on negative and cognitive symptoms are less well understood and more controversial. We observed that medication withdrawal led to increases in blood flow in three brain regions that perform important cognitive functions: the anterior cingulate, the prefrontal cortex, and the lateral cerebellum. The increase in blood flow in the frontal and cingulate cortex following medication withdrawal is particularly intriguing as these areas have been implicated in the pathophysiology of schizophrenia (Weinberger et al. 1986; Benes and Bird 1987; Andreasen et al. 1992). It is unclear whether these changes are related to a direct effect of the antipsychotic medication decreasing blood flow in these regions or if they reflect downstream consequences of a primary action on the basal ganglia. As the basal ganglia have a variety of regulatory functions, it could be hypothesized that an increase in blood flow and activity in this region may lead to more efficient frontal/cingulate and cerebellar function with a resultant decrease in blood flow. Two recent reports support this inference. Dolan et al. (1995) have noted that a dopamine agonist, apomorphine, modulated cerebral blood flow and cognitive activation in the anterior cingulate. In addition, Silbersweig and associates (Silbersweig et al. 1995) have reported increases in the anterior cingulate and left cerebellum during auditory hallucinations. Both these reports are consistent with the observations in the present study. More work is needed, however, in order to determine the circuits and chemical mechanisms by which antipsychotic medications exert their therapeutic effects on the cognitive and clinical symptoms of schizophrenia.

\section{ACKNOWLEDGMENTS}

This research was supported in part by NIMH Grants MH31593, MH40856 and MH43271, a Research Scientist Award, MH00625; and an Established Investigator Award from NARSAD.

\section{REFERENCES}

Alexander G, Crutcher M (1990): Functional architecture of basal ganglia: Neural substrates of parallel processing. Trends in Neurosci 13:266-271
Alexander G, DeLong M, Srick P (1986): Parallel organization of functionally segregated circuits linking basal gangiia and cortex. Ann Rev Neurosci 9:357-381

Andreasen N, Rezai K, Alliger R, Swayze V, Flaum M, Kirchner P, Cohen G, O'Leary D (1992): Hypofrontality in neuroleptic-naive patients and in patients with chronic schizophrenia: assessment with Xenon 133 single-photon emission computed tomography and the Tower of London. Arch Gen Psychiatry 49:943-958

Andreasen NC, Arndt S, Swayze V, Cizadlo T, Flaum M, O'Leary D, Ehrhardt J, Yuh WTC (1994a): Thalamic abnormalities in schizophrenia visualized through magnetic resonance image averaging. Science 266:294-298

Andreasen NC, Cizadlo T, Harris G, Swayze II V, O'Leary DS, Cohen G, Ehrhardt J, Yuh WTC (1993): Voxel processing techniques for the antemortem study of neuroanatomy and neuropathology using magnetic resonance imaging. J Neuropsychiatry \& Clin Neurosci 5:121-130

Andreasen NC, Flashman L, Flaum M, Arndt S, Swayze V, O'Leary DS, Ehrhardt JC, Yuh WTC (1994b): Regional brain abnormalities in schizophrenia measured with magnetic resonance imaging. JAMA 272:1763-1769

Andreasen NC, O'Leary DS, Cizadlo T, Arndt S, Rezai K, Watkins GL, Ponto LLB, Hichwa R (1995): Remembering the past: Two facets of episodic memory explored with positron emission tomography. Am J Psychiatry 152:1576-1585

Bartlett E, Wolkin A, Brodie J, LaSka E, Wolf A, Sanfilipo M (1991): Importance of pharmacologic control in PET studies: Effects of thiothixene and haloperidol on cerebral glucose utilization in chronic schizophrenia. Psych Res: Neuroimaging 40:115-124

Benes F, Bird E (1987): An analysis of the arrangement of neurons in the cingulate cortex of schizophrenic patients. Arch Gen Psychiatry 44:608-616

Breier A, Buchanan RW, Elkashef A, Munson RC, Kirkpatrick B, Gellad F (1992): Brain morphology and schizophrenia: A magnetic resonance imaging study of limbic, prefrontal cortex, and caudate structures. Arch Gen Psychiatry 49:921-926

Brodie J, Christman D, Fowler J (1984): Patterns of metabolic activity in the treatment of schizophrenia. Ann Neurology 15:Suppl S166-S169

Buchanan R, Breier A, Kirkpatrick B, Elkashef A, Munson R, Gellad F, Carpenter W (1993): Structural abnormalities in deficit and nondeficit schizophrenia. Am J Psychiatry 150(1):59-65

Buchsbaum M, Ingvar D, Kessler R, Walters R, Cappelletti J, van Kammen D, King A, Johnson J, Manning R, Flynn R, Mann L, Bunney W, Sokoloff L (1982): Cerebral glucography with positron tomography. Arch Gen Psychiatry 39:251-259

Buchsbaum M, Potkin S, Marshall J, Lottenberg S, Teng C, Heh C, Taffalla R, Reynolds C, Abel L, Plon L, Bunney W (1992a): Effects of clozapine and thiothixene on glucose metabolism rate in schizophrenia. Neuropsychopharmacology 6:115-163

Buchsbaum M, Potkin S, Siegel B, Lohr J, Katz M, Gottschalk L, Gulasekaram B, Marshall J, Lottenberg S, Teng C, Abel L, Pion L, Bunney W (1992b): Striatal metabolic 
rate and clinical response to neuroleptics in schizophrenia. Arch Gen Psychiatry 49:966-974

Buchsbaum M, Wu J, DeLisi L, Holcomb H, Hazlett E, Cooper-Langston K, Kessler R (1987): Positron emission tomography studies of basal ganglia and somatosensory cortex neuroleptic drug effects: Differences between normal controls and schizophrenic patients. Biol Psychiatry 22:479-494

Chakos M, Lieberman J, Bilder R, Borenstein M, Lerner G, Bogerts B, Wu H, Kinon B, Ashtari M (1994): Increase in caudate nuclei volumes of first-episode schizophrenic patients taking antipsychotic drugs. Am J Psychiatry 151:1430-36

Cizadlo T, Andreasen NC, Zeien G, Rajarethinam R, Harris G, O'Leary D, Swayze V, Arndt S, Hichwa J, Ehrhardt J, Yuh WTC (1994): Image registration issues in the analysis of multiple-injection $150 \mathrm{H} 2 \mathrm{O}$ PET studies: BRAINFIT. In SPIE-The International Society for Optical Engineering, 2168 Newport Beach, California: Society of Photo-Optical Instrumentation Engineers pp. 234-245

Cleghorn JM, Garnett ES, Nahmias C, Firnau G, Brown GM, Kaplan R, Szechtman H, Szechtman B (1989): Increased frontal and reduced parietal glucose metabolism in acute untreated schizophrenia. Psych Res 28:119-133

DeLisi L, Holcomb H, Cohen R, Pickar D, Carpenter W, Morihisa J (1985): Positron emission tomography in schizophrenic patients with and without neuroleptic medication. J Cerebral Blood Flow and Metab 5:201-206

Dolan R, Fletcher P, Frith C, Friston K, Frackowiak R, Grasby $P$ (1995): Dopaminergic modulation of impaired cognitive activation in the anterior cingulate cortex in schizophrenia. Nature 378:180-182

Elkashef A, Buchanan R, Gellad F, Munson R, Breier A (1994): Basal ganglia pathology in schizophrenia and tardive dyskinesia: An MRI quantitative study. Am J Psychiatry 151:752-755

Farde L, Hall H, Ehrin E, Sedvall G (1986): Quantitative analysis of D2 dopamine receptor binding in the living brain by PET. Science 231:258-261

Ginsberg M, Lockwood A, Busto R, Finn R (1982): A simplified in vivo autoradiographic strategy for the determination of regional cerebal blood flow by positron emission tomography: Theoretical considerations and validation studies in the rat. J Cerebral Blood Flow and Metab 2:89-98

Goldman-Rakic P, Selemon L (1990): New frontiers in basal ganglia research. Trends in Neurosci 13:241-244

Graybiel A (1990): Neurotransmitters and neuromodulars in the basal ganglia. Trends in Neurosci 13:244-254

Gur R, Resnick S, Gur R, Alavi A, Caroff S, Kushner M, Reivich M (1987): Regional brain function in schizophrenia: II. Repeated evaluation with positron emission tomography. Arch Gen Psychiatry 44:126-129

Heckers S, Heinsen H, Heinsen Y, Beckmann H (1991): Cortex, white matter, and basal ganglia in schizophrenia: A volumetric postmortem study. Biol Psychiatry 29:556-566

Herscovitch P, Markham J, Raichle M (1983): Brain blood flow measured with intravenous $\mathrm{H} 2150$. I. Theory and error analysis. J Nuc Med 24:782-789

Hokuma H, Shenton M, Nestor P, Kikinis R, Levitt J, Metcalf D, Wible C, O'Donnell B, Jolesz F, McCarley R (1997):
Caudate, putamen, and globus pallidus volumes in schizophrenia: A quantitative MRI study. Psych Res: Neuroimaging (in press)

Holcomb H, Cascella N, Thaker G, Medoff D, Dannals R, Tamminga C (1996): Functional sites of neuroleptic drug action in human brain: PET/FDG studies with and without haloperidol. Am J Psychiatry 153:41-49

Ingvar D, Franzen G (1974): Abnormalities of cerebral blood flow distribution in patients with chronic schizophrenia. Acta Psychiatrica Scand 15:425-462

Jernigan TL, Zisook S, Heaton RK, Moranville JT, Hesselink JR, Braff DL (1991): Magnetic resonance imaging abnormalities in lenticular nuclei and cerebral cortex in schizophrenia. Arch Gen Psychiatry 48:881-890

Keshavan M, Bagwell W, Haas G, Sweeney J, Schooler N, Pettegrew I (1994): Changes in caudate volume with neuroleptic treatment. Lancet 344:1434

Miller D, Rezai K, Alliger R, Andreasen N (1997): The effect of antipsychotic medication on relative cerebral blood flow in schizophrenia: Assessment with TC-99M HMPAO SPECT. Biol Psychiatry 41:550-559

Pearlson GD, Marsh L. (1993): Magnetic Resonance Imaging in Psychiatry. Washington, D. C., American Psychiatric Press

Pelizzari CA, Chen GTY, Spelbring DR, Weichselbaum RR, Chen C-T (1989): Accurate three-dimensional registration of CT, PET, and/or MRI images of the brain. J Computer Assisted Tomography 13:20-26

Raichle M, Martin W, Herscovitch P (1983): Brain bloodflow measured with H2150. II. Implementation and validation. J Nuc Med 24:790-798

Sedvall G, Blomquist G, DePaulis T, Ehrin E, Eriksson L, Farde L, Greitz T (1985): PET Studies on Brain Energy Metabolism and Dopamine Receptors in Schizophrenic Patients and Monkeys. New York, Plenum Press

Silbersweig D, E S, C F, Cahill C, Holmes A, Grootonk S, Seaward J, McKenna P, Chua S, Schnorr L, Jones T, Frackowiak R (1995): A functional neuroanatomy of hallucinations in schizophrenia. Nature 378:176-179

Smith A, Bolam J (1990): The neural network of the basal ganglia as revealed by the study of synaptic connections of identified neurons. Trends in Neurosci. 13:259-265

Swayze V, Andreasen N, Alliger R, Yuh W, Ehrhardt J (1992): Subcortical and temporal structures in affective disorder and schizoprhenia: A magnetic resonance imaging study. Biol Psychiatry 31:221-240

Talairach JTP (1988): Co-planar Stereotaxic Atlas of the Human Brain. New York, Thieme

Volkow N, Brodie J, Wolf A, Angrist B, Russell J, Cancro R (1986). Brain metabolism in patients with schizophrenia before and after acute neuroleptic administration. J Neurology, Neurosurgery, and Psychiatry 49:1199-1202

Weinberger D, Berman K, Illowsky B (1988): Physiological dysfunction of dorsolateral prefrontal cortex in schizophrenia: III. A new cohort and evidence for a monoaminergic mechanism. Arch Gen Psychiatry 45:609-615

Weinberger D, Berman K, Zee R (1986): Physiological dysfunction of dorsolateral prefrontal cortex in schizophrenia: I. Regional cerebral blood flow evidence. Arch Gen Psychiatry 43:114-124 
Wik G, Wiesel F, Sjogren I, Blomqvist G, Greitz T, StoneElander S (1989): Effects of sulpiride and chlorpromazine on regional glucose metabolism in schizophrenic patients as determined by positron emission tomography. Psychopharmacology 97:309-318

Wolkin A, Jaeger J, Brodie J, Wolf A, Fowler J, Rotrosen J, Gomez-Mont F (1985): Persistence of cerebral metabolic abnormalities in chronic schizophrenia as determined by positron emission tomography. Am J Psychiatry 142:564-571

Worsley KJ, Evans AC, Marrett S, Neelin P (1992): A three dimensional statistical analysis for CBF activation studies in human brain. J Cerebral Blood Flow and Metab 12:900-918 